\title{
Evaluation of children with ventricular arrhythmias
}

\author{
DOROTHY J. RADFORD, T. IZUKAWA, AND R. D. ROWE \\ From the Department of Paediatrics, Division of Cardiology, Hospital for Sick Children, Toronto, Canada
}

SUMMARY Ventricular arrhythmias are rare in childhood but may be associated with syncope and sudden death. This report describes 8 children with ventricular arrhythmias, 6 of whom suffered syncopal episodes. Ventricular tachycardia was documented in 5. One boy died suddenly. Complete cardiac investigation was carried out with exercise testing, Holter monitoring, echocardiography, cardiac catheterization, angiography, and electrophysiological studies. The spectrum of abnormalities related to the arrhythmias included prolapsing mitral valve, prolonged QT syndrome, sick sinus syndrome, congenital heart disease, cardiomyopathy, and idiopathic ventricular tachycardia. Exercise testing and Holter monitoring were particularly useful in documenting the arrhythmias and monitoring response to therapy.

Cardiac syncope may occur in children as a result of outflow obstruction (e.g. aortic stenosis) or from conduction defects and arrhythmias. Complete heart block resulting in Stokes-Adams attacks is infrequent in children (Molthan et al., 1962; Nakamura and Nadas, 1964) but the sick sinus syndrome, a recently recognized cause of syncopal episodes may occur more frequently (Radford and Izukawa, 1975; Scott et al., 1976). Ventricular tachycardia is a rare arrhythmia causing syncope in childhood (Videbaek et al., 1973; Hernandez et al., 1975).

Within a period of 12 months our Cardiology Division was presented with the problems of 6 children with syncope and ventricular arrhythmias, of whom 3 had documented ventricular tachycardia. Another 2 had ventricular tachycardia without syncope. Such children carry the risk of sudden death and the clinician must therefore make careful investigations to determine aetiology, precipitating factors, and suitable treatment. This report reviews the evaluation of these 8 patients, the wide spectrum of aetiologies, and methods of assessment of therapeutic regimens.

\section{Methods}

All 8 children were assessed clinically by electrocardiograms (ECG), exercise stress testing, echocardiography, and cardiac catheterization with angiography. Electrophysiological studies were done in 6 and Holter monitoring in 5.

Exercise testing was conducted on a treadmill with $10 \%$ elevation. The protocol was based on that of

Received 2 September 1976
Ellestad et al. (1969). The child exercised for 10 minutes-3 min at $1.7 \mathrm{mph}, 2 \mathrm{~min}$ at $3 \mathrm{mph}, 2 \mathrm{~min}$ at $4 \mathrm{mph}$, and finally $3 \mathrm{~min}$ at $5 \mathrm{mph}$. A physician watched a continuous ECG oscilloscope monitor and recorded arrhythmias as well as routine recordings at 1-minute intervals during the test and for 8 minutes after.

Holter monitoring (Holter, 1961) or dynamic ECG was performed with the child wearing a cassette tape recorder for 16 hours. Playback was made on a rapid scanner (Medcraft CDC 70) and arrhythmias were recorded by direct write out. Echocardiography was performed using an Ekoline 20 ultrasonoscope and a Cambridge strip chart recorder. Cardiac catheterization was done from a percutaneous approach to the femoral vessels. Routine pressure and $\mathrm{O}_{2}$-saturation data were obtained. Angiography included a selective contrast injection into the aortic root to delineate the coronary arteries, and other views to outline ventricular anatomy and function.

His bundle recordings by intracardiac ECG were obtained by the standard method of Scherlag et al. (1969). Normal values for children were taken from the tables of Abella et al. (1972). Sinus node recovery times were recorded after high atrial pacing for 1 minute and timing the interval from the last paced beat to the first spontaneous sinus beat. A normal time was $<150 \%$ resting $R R$ interval.

Ventricular tachycardia was defined as a sequence of three or more wide, abnormal QRS complexes at a rate between 150 and $250 / \mathrm{min}$. In order to exclude supraventricular tachycardia with aberrant conduction it was necessary to observe other criteria, namely (i) a dissociated atrial rhythm slower than 
the ventricular rate, (ii) capture and fusion beats, (iii) ventricular ectopic beats occurring during sinus rhythm with the same configuration as the complexes of the tachycardia (Lown et al., 1973).

\section{Case reports}

Case 1. At age 11 years this girl had a syncopal episode on a ski slope and was promptly resuscitated. Her past history included the occurrence of cardiac arrhythmias during general anaesthesia for dental and orthopaedic procedures at the age of 6 years, and a report of 'concussion' after falling from a bicycle at age 8 . Her parents had observed deterioration of her motor and mental skills.

Detailed assessments were made. Intelligence testing confirmed retardation. There was no definite neurological abnormality, but the electroencephalogram showed poorly organized rhythms. At the initial examination auscultatory findings were normal and the ECG showed normal QRS complexes and ST-T wave segments, with a wandering atrial pacemaker. An exercise ECG precipitated multifocal ventricular ectopic beats and runs of ventricular tachycardia (Fig. 1). The echocardio-

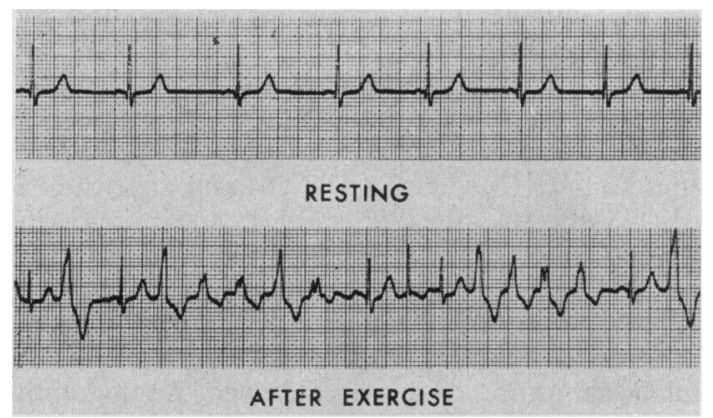

Fig. 1 Case 1. ECG after exercise. Ventricular tachycardia and multifocal ventricular ectopic beats.

gram showed prolapse of the posterior leaflet of the mitral valve. At cardiac catheterization no other anatomical or haemodynamic abnormalities were found and the sinus node recovery time and His bundle intervals were normal Supraventricular tachycardia confirmed by His spike recordings was induced by an isoprenaline infusion. Otherwise, only occasional supraventricular and ventricular ectopic beats occurred.

Treatment with oral propranolol was started and serial exercise testing was done to monitor this therapy. Initially multifocal ventricular ectopics and ventricular tachycardia continued to occur with exercise, but with adequate doses only occasional unifocal ventricular ectopic beats were precipitated by this stress testing. Also, a midsystolic click and late systolic murmur of mitral valve prolapse became audible. She now remains symptom free.

Case 2. This boy was born by caesarean section because of fetal heart irregularities and a fall in rate to $100 / \mathrm{min}$. At birth there was ECG evidence of $2: 1$ heart block and frequent ventricular ectopic beats. On the first day of life he developed short runs of ventricular tachycardia and a temporary transvenous pacing catheter was inserted. Intermittent sinus rhythm occurred. Eventually, the child stabilized with an adequate heart rate and the rhythm varying from normal to $2: 1$ heart block. He was discharged without a pacemaker or drug therapy. A close follow-up was maintained and from age 11 months he was always found in sinus rhythm, but there was prolongation of the QT interval on all subsequent ECGs. He had no deafness and remained well till 9 years of age when he had a syncopal episode and was admitted to hospital for assessment.

The ECG showed sinus rhythm with a $1: 1$ conduction and $\mathrm{Q}-\mathrm{T}_{\mathrm{c}}$ prolongation of $\mathbf{0 . 5 0}$ seconds (Fig. 2). On exercise testing he developed $2: 1$ atrioventricular block and did not increase his ventricular rate beyond $100 / \mathrm{min}$. After exercise he had a short run of ventricular tachycardia during which he was aware of palpitations. Holter monitoring also showed episodes of ventricular tachycardia (Fig. 3). Two further syncopal episodes occurred and he was started on intravenous lignocaine and a temporary transvenous pacemaker inserted. Cardiac catheterization showed normal anatomy and haemodynamics and normal His intervals at rest. However, with atrial pacing the $\mathrm{H}-\mathrm{V}$ interval lengthened and atrioventricular block developed. Sinus node recovery times were also prolonged. A stellate ganglion block was then performed, but this failed to change the Q-T interval.

The pacemaker and lignocaine were discontinued and he was given oral propranolol. This therapy was assessed by Holter monitoring and a further exercise test. No further ventricular tachycardia occurred. He has remained asymptomatic.

Case 3. From the age of 6 years this boy had episodes of dizziness and loss of consciousness. He was initially considered to have a seizure disorder and treated with diphenylhydantoin. However, he continued to have frequent attacks and it was noted that the episodes occurred with exercise and were preceded by palpitations. He had a full cardiological assessment at age 12 .

Clinical examination showed a functional systolic 


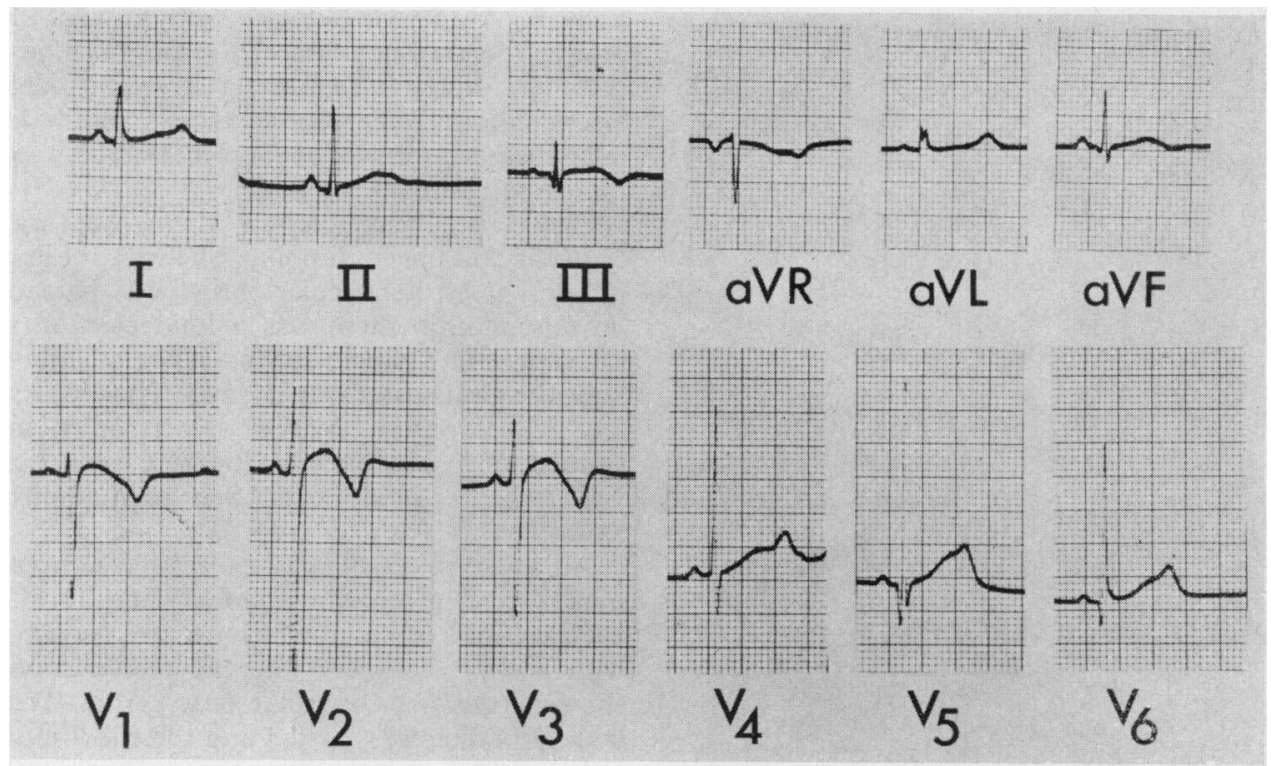

Fig. 2 Case 2. ECG shows $Q T$ interval of 0.50 seconds.

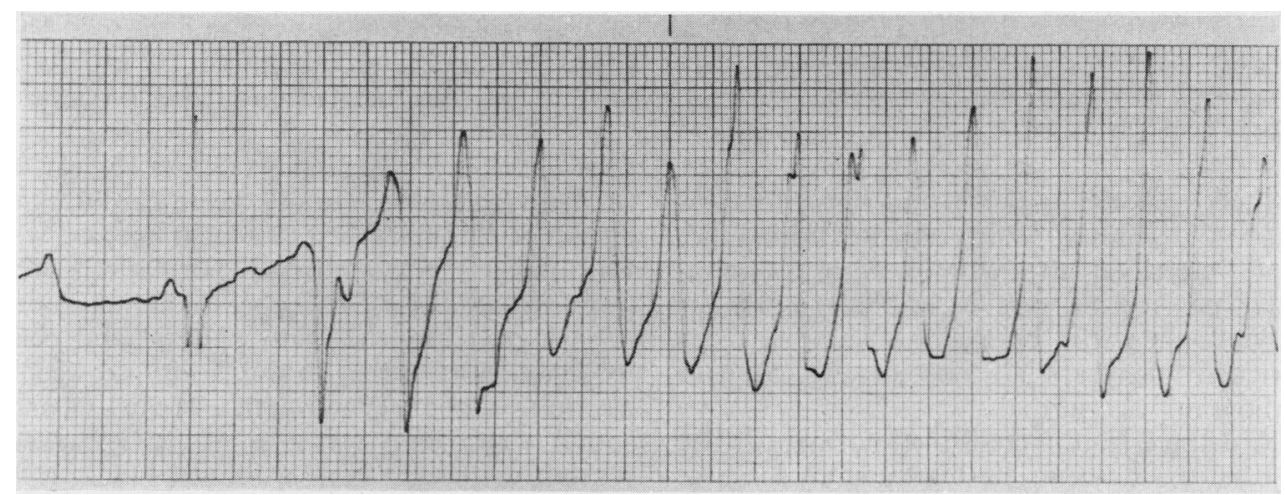

Fig. 3 Case 2. Recording from the Holter monitor shows ventricular tachycardia.

murmur which disappeared on standing. The resting ECG showed sinus bradycardia of $45 / \mathrm{min}$ with sinus arrhythmia and occasional junctional beats. The QRS complexes were normal and there was a normal QT interval. On exercise his heart rate increased to $100 /$ min but then ventricular bigeminy developed. Immediately after exercise multifocal ventricular ectopic beats were recorded and the heart rate slowed to $48 / \mathrm{min}$ one minute after completion of the test (an abnormal response) (Fig. 4). The echocardiogram was normal. Cardiac catheterization showed no abnormalities. His-bundle studies and sinus node recovery times were normal.

The patient was started on oral propranolol. In spite of normal sinus node recovery times on electrophysiological studies, it is considered that this boy may have the sick sinus syndrome, diagnosed on the basis of inappropriate sinus bradycardia and an abnormal exercise response. Since he has responded to drug therapy with no further syncope, a cardiac pacemaker has not yet been considered.

Case 4. A 12-year-old girl was assessed because of frequent palpitations and episodes of dizziness which she observed particularly with excitement and exercise. There was no significant past history. Clinical examination was normal except for an irregular pulse. ECG showed sinus bradycardia of 


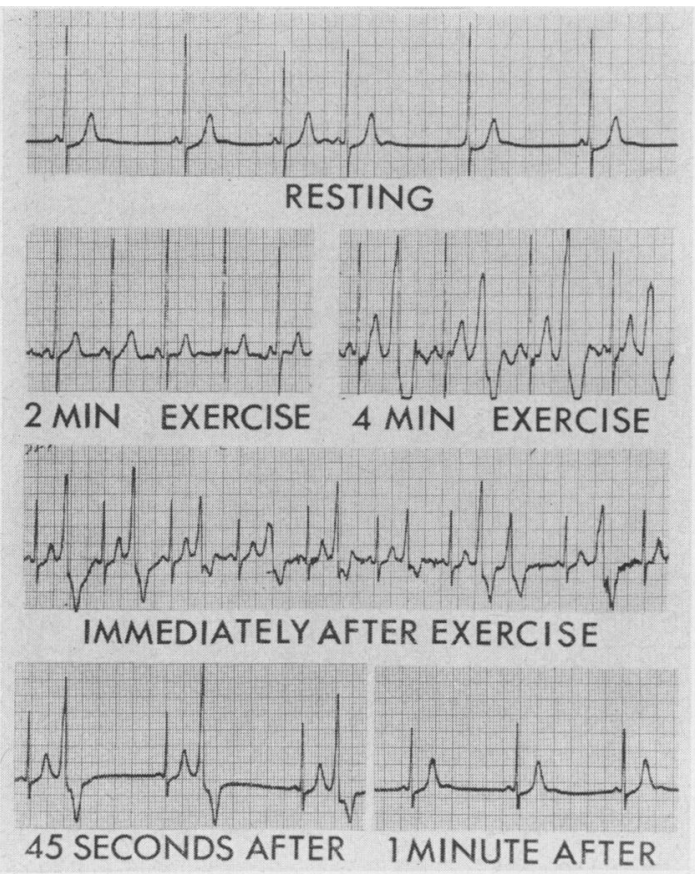

Fig. 4 Case 3. Exercise test. Ventricular ectopics developed and the heart rate slowed to $48 / \mathrm{min}$, one minute after completion of the test.

46/min, junctional escape beats, and runs of supraventricular tachycardia. With exercise testing her heart rate increased to $210 / \mathrm{min}$ with a supraventricular tachycardia and occasional ventricular ectopic beats, then with cessation of exercise, runs of ventricular tachycardia occurred (Fig. 5). Her echocardiogram was normal.

Cardiac catheterization confirmed normal cardiac anatomy, but the left ventricle delineated by selective angiography appeared to have reduced contractility. The coronary arteries were normal and intracardiac pressures were normal. Electrophysiological studies showed a markedly prolonged sinus node recovery time. The His intervals were normal. Ectopic beats showed retrograde conduction to the His bundle, demonstrating a ventricular origin. Exercise by leg raising movements during the study was insufficient to produce an increase in heart rate. Isoprenaline infusion in low dosage produced supraventricular tachycardia and occasional ventricular ectopics.

The final diagnosis was brady-tachycardia syndrome (a variant of sick sinus syndrome) with ventricular tachycardia as an exercise-induced rhythm. She has been treated with oral propranolol. Episodes of palpitations continue but less frequently. There has been no syncope.
Case 5. A 15-year-old girl with known tricuspid atresia and transposition of the great arteries had a pallative superior vena cava to right pulmonary artery shunt created (Glenn anastomosis). One year later she had two syncopal episodes. She was taking no drug therapy at the time.

On clinical examination there was moderate cyanosis and finger clubbing. She was not in cardiac failure. A left ventricular thrust was palpable and on auscultation there was a loud ejection systolic murmur and a single second heart sound. Neurological examination was normal. The ECG showed left axis deviation, biatrial hypertrophy, and left ventricular hypertrophy. Also, there were occasional ventricular ectopic beats. She was admitted for assessment.

An exercise ECG was cancelled when a preliminary resting recording showed multifocal ventricular ectopics, some of which occurred consecutively with a short coupling interval. Holter monitoring showed runs of ventricular tachycardia. Treatment with quinidine was started and the effect monitored by serial Holter recordings. Increasing dosage failed to suppress all serious arrhythmias (Fig. 6), and it was not till propranolol was added that the runs of ventricular ectopics were suppressed. She continues to take a combination of quinidine and propranolol and has had no further syncope.

Case 6. While jogging in gym class a 15 -year-old boy suddenly collapsed. He was given cardiopulmonary resuscitation and rushed to a local hospital where he was found to be in ventricular fibrillation. Defibrillation was successful. Subsequent examination showed neurological sequelae with parietal and cerebellar dysfunction. Cardiac examination showed a soft ejection systolic murmur with a normal second heart sound. Chest $x$-ray was normal. ECG showed sinus rhythm with right bundle branch block, right axis deviation, and left atrial hypertrophy. There were no ectopic beats.

A 16-hour Holter record showed sinus rhythm throughout with heart rate varying from 50 to $100 /$ min and occasional single unifocal ventricular ectopic beats. On exercise testing the heart rate increased from 65 to $185 / \mathrm{min}$ and only one ventricular ectopic occurred. After the test, sinus arrest and junctional bradycardia at $45 / \mathrm{min}$ occurred before sinus rhythm resumed. An echocardiogram showed thickened ventricular walls and septum, enlargement of the left atrium and both ventricular cavities, and decreased contractility.

Previous cardiological data on the patient were reviewed. He had been studied twice previously by cardiac catheterization. The diagnosis from the first study was mild pulmonary valve stenosis. At 


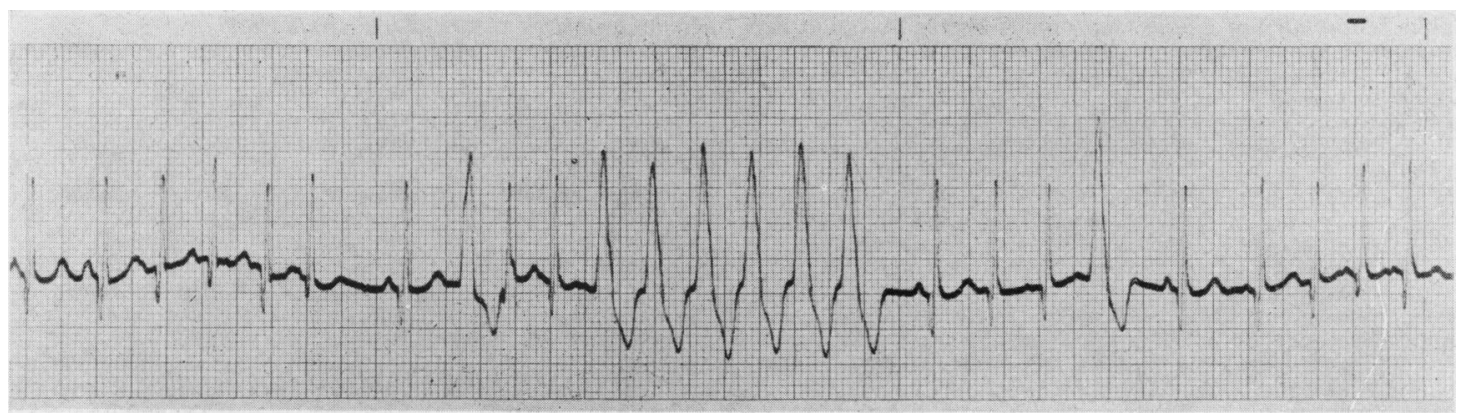

Fig. 5 Case 4. Ventricular tachycardia after exercise.

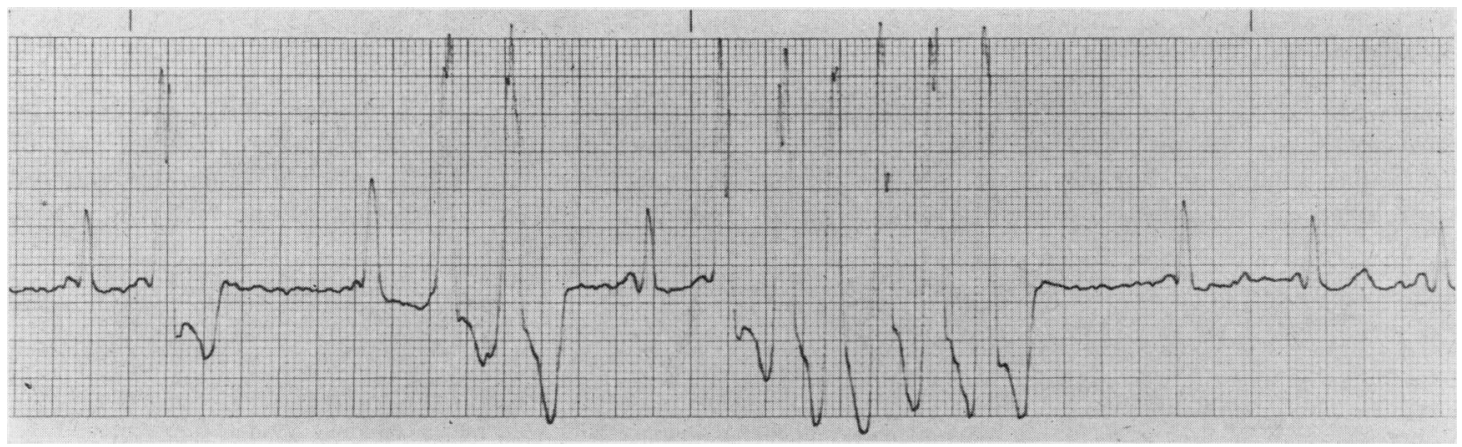

Fig. 6 Case 5. Recording from Holter monitor shows ventricular ectopics and ventricular tachycardia.

the age of 11 years a second catheterization showed pulmonary infundibular narrowing with a resting gradient of $20 \mathrm{mmHg}$ which increased to $35 \mathrm{mmHg}$ with an isoprenaline infusion. No gradient was recorded across the left ventricular outflow tract before or after provocation.

A third catheter study was performed after his syncopal episode. Isoprenaline produced a gradient of $14 \mathrm{mmHg}$ across the left ventricular outflow tract and of $20 \mathrm{mmHg}$ across the pulmonary infundibulum. Angiography showed thickening of the ventricular walls with diminished contractility. The interventricular septum was abnormally thick. His-bundle intervals were normal but sinus node recovery time was abnormally prolonged. As an extensive family history of obstructive cardiomyopathy has since been found, the concluding diagnosis is familial hypertrophic cardiomyopathy and sinus node dysfunction. The patient has been started on propranolol therapy and remains well.

Case 7. A 7-year-old boy had a history of dizziness and three definite syncopal attacks. ECG showed sinus rhythm with unifocal ventricular ectopics with bigeminy and occasional trigeminy. The nonectopic QRS-T wave complexes were normal. Clinical examination, chest $x$-ray, echocardiogram, and electroencephalogram were normal. Cardiac catheterization showed normal anatomy and haemodynamics, but on angiography the left ventricular contractility appeared reduced.

A 16-hour Holter recording showed disappearance of the ectopics with sleep and recurrence on arousal. Exercise testing suppressed the ectopics and he developed normal sinus rhythm with an appropriate increase in heart rate. Bigeminal rhythm returned after exercise. No change in these responses occurred when taking oral propranolol. Challenge testing by carotid sinus massage, Valsalva manoeuvres, intravenous phenylephrine (Neosynephrine), and isoprenaline also produced no variation of the bigeminy. Since bigeminy alone was not considered dangerous, he was discharged on propranolol. Sudden death occurred 6 months later.

Case 8. An asymptomatic 12-year-old boy with no past medical history was seen by his paediatrician for an annual check-up. Physical examination was normal except for an irregular heart beat. ECG showed short runs of ventricular tachycardia. Therefore cardiological assessment was requested.

Cardiac examination, chest $x$-ray, and echocardio- 
Table Summary of clinical data and positive investigations of 8 children with ventricular arrhythmias

\begin{tabular}{|c|c|c|c|}
\hline $\begin{array}{l}\text { Case no. } \\
\text { / sex }\end{array}$ & $\begin{array}{l}\text { Symptoms } \\
\text { and age }(y r)\end{array}$ & Investigations & Diagnosis \\
\hline $1 \mathrm{~F}$ & Syncope, age 9 & $\begin{array}{l}\text { Exercise test precipitated multifocal VEs and VT; mitral valve prolapse } \\
\text { on echocardiogram }\end{array}$ & Mitral valve prolapse syndrome \\
\hline $2 \mathrm{M}$ & Syncope, age 11 & $\begin{array}{l}\text { Exercise caused } 2: 1 \text { heart block and VT; VT documented on Holter } \\
\text { monitoring; prolonged SNRT and HV interval }\end{array}$ & $\begin{array}{l}\text { Prolonged QT syndrome; congenital } \\
\text { second-degree heart block }\end{array}$ \\
\hline $3 \mathbf{M}$ & Syncope, age 6 & Multifocal VEs and sinus bradycardia after exercise & Probable sick sinus syndrome \\
\hline $4 \mathrm{~F}$ & $\begin{array}{l}\text { Palpitations, } \\
\text { dizziness, age } 12\end{array}$ & $\begin{array}{l}\text { VT after exercise; prolonged SNRT; reduced contractility of LV } \\
2\end{array}$ & $\begin{array}{l}\text { Brady-tachycardia syndrome } \\
\text { (variant of sick sinus syndrome) }\end{array}$ \\
\hline $5 \mathrm{~F}$ & Syncope, age 16 & VT and multifocal VEs on Holter & Tricuspid atresia; Glenn shunt \\
\hline $6 \mathrm{M}$ & $\begin{array}{l}\text { Syncope (cardiac } \\
\text { arrest), age } 15\end{array}$ & $\begin{array}{l}\text { VE and junctional bradycardia after exercise; minor LV and RV outflow } \\
\text { gradients induced by isoprenaline; prolonged SNRT }\end{array}$ & $\begin{array}{l}\text { Familial hypertrophic } \\
\text { cardiomyopathy; sinus node } \\
\text { dysfunction }\end{array}$ \\
\hline $7 \mathbf{M}$ & Syncope, age 7 & $\begin{array}{l}\text { Bigeminy disappeared with exercise and sleep; reduced contractility } \\
\text { of LV }\end{array}$ & Idiopathic VEs; sudden death \\
\hline $8 \mathbf{M}$ & $\begin{array}{l}\text { Asymptomatic, } \\
\text { age } 12\end{array}$ & $\begin{array}{l}\text { VT and sinus bradycardia on ECG; VEs with bigeminy and coupling } \\
\text { on exercise and Holter }\end{array}$ & Idiopathic paroxysmal VT \\
\hline
\end{tabular}

$\mathrm{VT}=$ ventricular tachycardia; $\mathrm{VE}=$ ventricular ectopic; $\mathrm{SNRT}=$ sinus node recovery time; $\mathrm{HV}=\mathrm{His}$-bundle to ventricle; $\mathrm{LV}=$ left ventricle; RV = right ventricle.

gram were normal. Our resting ECG showed sinus bradycardia of $52 / \mathrm{min}$ and periods of unifocal ventricular bigeminy, but no other abnormalities. A pre-exercise recording showed closely coupled ventricular ectopics. However, with exercise the ectopics disappeared and a maximum heart rate of $170 /$ min was achieved. Ventricular bigeminy recurred $1 \frac{1}{2}$ minutes after completion of the test (Fig. 7). A

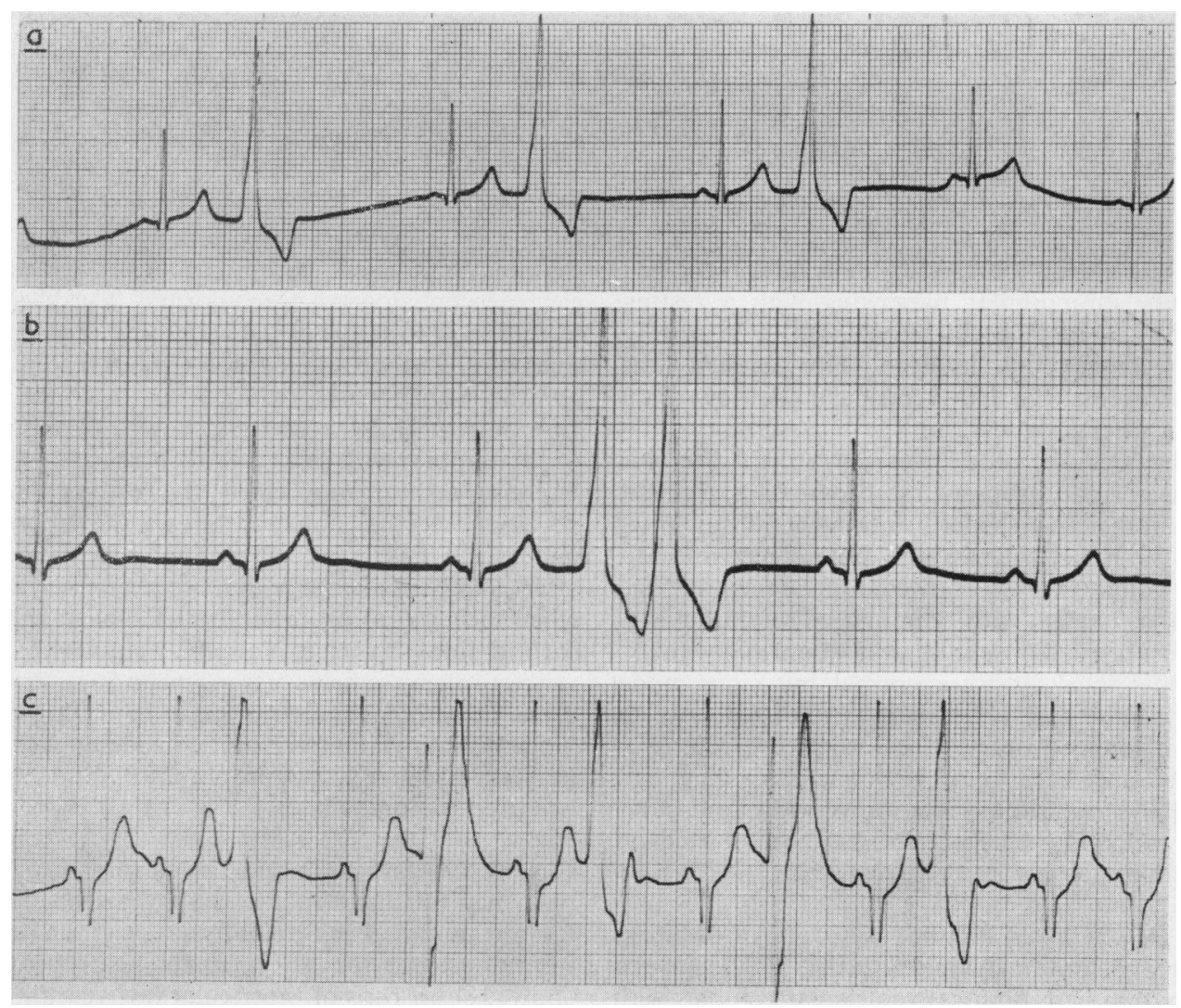

Fig. 7 Case 8. (a) Ventricular bigeminy. (b) Closely coupled ventricular ectopics. (c) Ventricular ectopics $1 \frac{1}{2}$ min after completion of exercise test. 
16-hour Holter monitor also recorded intermittent ventricular ectopics with bigeminy and occasional consecutive beats. Cardiac catheterization confirmed a haemodynamically normal heart with normal electrophysiological studies.

Our final diagnosis is idiopathic paroxysmal ventricular tachycardia. Since it is a potentially dangerous arrhythmia, suppressive therapy with propranolol was started and the effect monitored by repeat Holter recordings and exercise testing. Complete elimination of ventricular ectopics has not been achieved but he remains asymptomatic.

\section{Discussion}

Although ventricular arrhythmias are rare in childhood, their association with syncope and sudden death is established (Berg, 1960; Horan and Venables, 1962; Palaganas et al., 1965; Wennevold and Sandøe, 1970). Thus if arrhythmias are suspected in children, it is essential to determine their nature and aetiology.

Well-known causes of ventricular arrhythmias are ischaemic heart disease, myocarditis, and electrolyte imbalances, particularly hyperkalaemia. Though coronary artery disease is the commonest cause of ventricular tachycardia (Armbrust and Levine, 1950), it is rare in childnen. We ensured that coronary artery abnormalities were excluded by making angiographic delineation at cardiac catheterization. Echocardiography and ventricular angiography were useful in excluding resectable cardiac tumours, a documented cause of ventricular tachycardia in children (Engle et al., 1974).

Our patients presented a wide spectrum of cardiac abnormalities related to their arrhythmias-mitral valve prolapse, prolonged QT syndrome, sick sinus syndrome, congenital heart disease, cardiomyopathy, and idiopathic ventricular tachycardia.

The mitral valve prolapse syndrome is now widely diagnosed clinically (systolic click murmur syndrome) and by echocardiography, and its prevalence is estimated at between 1.4 and $6 \%$ of the general population (Devereux et al., 1976). The association of atrial and ventricular arrhythmias with this syndrome is established and may be related to disturbances of ventricular myocardial motion (Gooch et al., 1972; Winkle et al., 1975, 1976). Fortunately sudden death is rare (Shappell et al., 1973; Jeresaty, 1976). A warning of syncope and occurrence of exercise-induced arrhythmias have been useful in indicating the need for antiarrhythmic therapy. Propranolol is the current drug of choice and was given to our patient (Case 1).

The syndrome of QT interval prolongation, congenital deafness, syncope, and sudden death was described by Jervell and Lange-Nielsen in 1957. Subsequently the same features have been found in patients with normal hearing (Romano-Ward syndrome). Our patient (Case 2) fits the latter category. However, he also had 2:1 atrioventricular block at birth. Thus, infection or other intrauterine insult may have been responsible. In certain patients with prolonged QT interval syndrome, left stellate ganglion blockage has been useful in reducing the QT interval and eliminating symptoms (Schwartz and Malliani, 1975). This was tried in our patient, but was not effective. Propranolol was then given, as it has been the most beneficial drug for treatment of this condition (Vincent et al., 1974).

Diagnosis of the sick sinus syndrome in children has been discussed recently (Nugent et al., 1974; Radford and Izukawa, 1975; Scott et al., 1976). Syncope may occur from sinus arrest and asystole, or from ventricular arrhythmias when lower cardiac pacemakers take over. Insertion of an artificial cardiac pacemaker is often indicated and may yet become necessary in our patients (Cases 3 and 4) who are presently responding well to drug therapy.

Ventricular tachycardia has been described previously in children with cyanotic congenital heart disease (McDonald et al., 1963; DeGuzman and Silver, 1970). Irritable foci from myocardial ischaemia may be the cause of the arrhythmias in these cases and in our patient with tricuspid atresia (Case 5).

Viral myocarditis may precipitate ventricular arrhythmias (Meehan and Bertrand, 1970) as may other cardiomyopathies. Though our patient (Case 6) had a family history of hypertrophic cardiomyopathy, cardiac catheterization evidence indicated minimal outflow tract obstruction but abnormal ventricular function. His problems were predominantly due to arrhythmias. Propranolol was the therapy of choice to suppress arrhythmias and to reduce any muscular outflow tract obstruction.

Although careful investigation has shown cardiac abnormalities on many of our patients, 2 were classified as idiopathic (Cases 7 and 8). These 2 children presented our most difficult management problems. In spite of a history of syncope, Case 7 was never observed to have more than ventricular bigeminy and trigeminy with the various challenge tests. However, sudden death occurred after his discharge from hospital. Case 8 was totally asymptomatic but had one documented run of ventricular tachycardia and evidence of bigeminy and coupling. Complete elimination of the ventricular ectopics has not been achieved. Idiopathic cases have been reported in the literature (Lesch et al., 1967; Hernandez et al., 1975). However, these cases were not studied by echocardiography or cardiac cathe- 
terization, so the abnormalities discussed above were not excluded. We feel that full investigation is important to exclude treatable conditions such as coronary artery abnormalities and cardiac tumours. Also knowledge of underlying cardiac lesions assists planning of subsequent therapy, such as use of cardiac pacemakers.

Exercise electrocardiography was most useful in documenting arrhythmias in our patients. Wennevold et al. (1965) emphasized its use as a diagnostic tool in children with syncope, and subsequent reports have confirmed its importance. Exercise testing is recommended for the detection of arrhythmias in patients with mitral leaflet prolapse syndrome (Gooch et al., 1972), sick sinus syndrome (Scott et al., 1976), and with QT abnormalities (Bernuth et al., 1973). In our experience the abnormal rhythms were detected more quickly and accurately by exercise testing than by Holter monitoring. However, the latter was useful, particularly in situations where it was dangerous to exercise the patient (e.g. Case 5).

When drug therapy for ventricular arrhythmias was started we used serial exercise testing and Holter monitoring to assess its adequacy. If serious arrhythmias persisted, drug dosage was increased until the arrhythmia was eliminated. We believe that such monitoring of therapeutic effect is essential for treating potentially fatal arrhythmias.

\section{References}

Abella, J. B., Teixeira, O. H., Misra, K. P., and Hastreiter, A. R. (1972). Changes of atrioventricular conduction with age in infants and children. American Journal of Cardiology, 30, 876-883.

Armbrust, C. A., and Levine, S. A. (1950). Paroxysmal ventricular tachycardia: a study of one hundred and seven cases. Circulation, 1, 28-40.

Berg, K. J. (1960). Multifocal ventricular extrasystoles with Adams-Stokes syndrome in siblings. American Heart Journal, 60, 965-970.

Bernuth, G., Belz, G. G., Evertz, W., and Stauch, M. (1973). QTU-abnormalities, sinus bradycardia and AdamsStokes attacks due to ventricular tachyarrhythmia. Acta Paediatrica Scandinavica, 62, 675-679.

DeGuzman, A., and Silver, W. (1970). Ventricular tachycardia and transposition of the great arteries. American Journal of Diseases of Children, 119, 278-279.

Devereux, R. B., Perloff, J. K., Reichek, N., and Josephson, M. E. (1976). Mitral valve prolapse. Circulation, 54, 3-14. Ellestad, M. H., Allen, W., Wan, M. C. K., and Kemp, G. L. (1969). Maximal treadmill stress testing for cardiovascular evaluation. Circulation, 39, 517-522.

Engle, M. A., Ebert, P. A., and Redo, S. F. (1974). Recurrent ventricular tachycardia due to resectable cardiac tumour. Circulation, 50, 1052-1057.

Gooch, A. S., Vicencio, F., Maranhao, V., and Goldberg, H. (1972). Arrhythmias and left ventricular asynergy in the prolapsing mitral leaflet syndrome. American Journal of Cardiology, 29, 611-620.
Hernandez, A., Strauss, A., Kleiger, R. E., and Goldring, D. (1975). Idiopathic paroxysmal ventricular tachycardia in infants and children. Journal of Pediatrics, 86, 182-188.

Holter, N. J. (1961). New method for heart studies. Science, 134, 1214-1220.

Horan, M., and Venables, A. W. (1962). Paroxysmal tachycardia with episodic unconsciousness. Archives of Disease in Childhood, 37, 82-85.

Jeresaty, R. M. (1976). Sudden death in the mitral valve prolapse-click syndrome. American Journal of Cardiology, 37, 317-318.

Jervell, A., and Lange-Nielsen, F. (1957). Congenital deafmutism, functional heart disease with prolongation of the Q-T interval, and sudden death. American Heart Journal, $54,59-68$.

Lesch, M., Lewis, E., Humphries, J. O'N., and Ross, R. S. (1967). Paroxysmal ventricular tachycardia in the absence of organic heart disease. Annals of Internal Medicine, 66, 950-960.

Lown, B., Temte, J. V., and Arter, W. J. (1973). Ventricular tachyarrhythmias. Clinical aspects. Circulation, 47, 1364-1381.

McDonald, L., Resnekov, L., and Ross, D. (1963). Resistant ventricular tachycardia a year after surgical correction of Fallot's tetralogy, treated by external electrical countershock. Lancet, 2, 708-709.

Meehan, W. F., and Bertrand, C. A. (1970). Ventricular tachycardia associated with echovirus infection. Journal of the American Medical Association, 212, 1701-1703.

Molthan, M. E., Miller, R. A., Hastreiter, A. R., and Paul, M. H. (1962). Congenital heart block with fatal AdamsStokes attacks in childhood. Pediatrics, 30, 32-41.

Nakamura, F. F., and Nadas, A. S. (1964). Complete heart block in infants and children. New England Journal of Medicine, 270, 1261-1268.

Nugent, E. W., Varghese, P. J., Pieroni, D. R., and Rowe, R. D. (1974). Sluggish sinus syndrome as part of congenital heart disease. (Abst.) American Journal of Cardiology, 33, 160.

Palaganas, M. C., Fay, J. E., and Delahaye, D. J. (1965). Paroxysmal ventricular tachycardia in childhood. Journal of Pediatrics, 67, 784-791.

Radford, D. J., and Izukawa, T. (1975). Sick sinus syndrome. Symptomatic cases in children. Archives of Disease in Childhood, 50, 879-885.

Scherlag, B. J., Lau, S. H., Helfant, R. H., Berkowitz, W. D., Stein, E., and Damato, A. N. (1969). Catheter technique for recording His bundle activity in man. Circulation, 39, 13-18.

Schwartz, P. J., and Malliani, A. (1975). Electrical alternation of the T-wave: clinical and experimental evidence of its relationship with the sympathetic nervous system and with the long Q-T syndrome. American Heart Journal, 89, 45-50.

Scott, O., Macartney, F. J., and Deverall, P. B. (1976). Sick sinus syndrome in children. Archives of Disease in Childhood, 51, 100-105.

Shappell, S. D., Marshall, C. E., Brown, R. E., and Bruce, T. A. (1973). Sudden death and the familial occurrence of mid-systolic click, late systolic murmur syndrome. Circulation, 48, 1128-1134.

Videbaek, J., Andersen, E. D., Jacobsen, J. R., Sandøe, E., and Wennevold, A. (1973). Paroxysmal tachycardia in infancy and childhood. II. Paroxysmal ventricular tachycardia and fibrillation. Acta Paediatrica Scandinavica, 62, 349-357.

Vincent, G. M., Abildskov, J. A., and Burgess, M. J. (1974). Q-T interval syndromes. Progress in Cardiovascular Disease, 16, 523-530. 
Wennevold, A., and Sandøe, E. (1970). Paroxysmal malignant arrhythmias in childhood and adolescence. Symposium on Cardiac Arrhythmias, p. 767. Ed. by E. Sandøe, E. FlenstedJensen and K. H. Olesen. Astra, Södertälje.

Wennevold, A., Melchior, J. C., and Sandøe, E. (1965). Adams-Stokes syndrome in children without organic heart disease. Electrocardiogram after exercise as a diagnostic tool. Acta Medica Scandinavica, 177, 557-563.

Winkle, R. A., Lopes, M. G., Fitzgerald, J. W., Goodman, D. J., Schroeder, J. S., and Harrison, D. C. (1975).
Arrhythmias in patients with mitral valve prolapse. Circulation, 52, 73-81.

Winkle, R. A., Lopes, M. C., Popp, R. L., and Hancock, E. W. (1976). Life-threatening arrhythmias in the mitral valve prolapse syndrome. American Journal of Medicine, 60, 961-967.

Correspondence to Dr. T. Izukawa, Hospital for Sick Children, 555 University Avenue, Toronto, Ontario M5G 1X8, Canada. 